\title{
Production of Nanopowders of Metal Oxides Using Pulsed Electron Beam in Low Pressure Gas
}

\author{
S. Yu. Sokovnin ${ }^{1,2}$ and V. G. Il'ves ${ }^{1}$ \\ ${ }^{1}$ Institute of Electrophysics, Ural Branch RAS, 106 Amundsen St., Ekaterinburg 620216, Russia \\ ${ }^{2}$ Ural Federal University, 19 Mira St., Ekaterinburg 620002, Russia
}

Correspondence should be addressed to V. G. Il’ves, ilves@iep.uran.ru

Received 2 April 2012; Accepted 31 May 2012

Academic Editors: A. M. Ali, Y. Dai, A. Kajbafvala, A. Nasibulin, and A. Pyatenko

Copyright ( $\odot 2012$ S. Yu. Sokovnin and V. G. Il'ves. This is an open access article distributed under the Creative Commons Attribution License, which permits unrestricted use, distribution, and reproduction in any medium, provided the original work is properly cited.

\begin{abstract}
The installation for production of metal oxide nanopowders was created. The method involves evaporation of the target by a pulsed-electron beam, condensation of the vapors of the material in a low-pressure gas, and deposition of nanopowders on a cold large-area crystallizer. In a new installation, a higher-power electron gun with a hollow cathode, which ensures the formation of the current pulse of the electron beam with amplitude up to $1 \mathrm{~A}$ and a duration of $100 \mu$ s, and a crystallizer of a larger diameter $(0.3 \mathrm{~m})$ and length $(0.5 \mathrm{~m})$, which makes it possible to decrease the agglomeration, were used. The results of the evaporation of targets made of $\mathrm{YSZ}, \mathrm{CeGdO}_{x}, \mathrm{Zn}-\mathrm{ZnO}, \mathrm{Al}_{2} \mathrm{O}_{3}$, and $\mathrm{ZnO}$ were presented. Room-temperature ferromagnetism has been observed in $\mathrm{YSZ}$, $\mathrm{Zn}-\mathrm{ZnO}$, and $\mathrm{Cu}(\mathrm{Al})$-doped $\mathrm{Al}_{2} \mathrm{O}_{3}$. The proposed method makes it possible to obtain nanopowders of oxides with a characteristic particle size of 3-5 nm and agglomerates consisting of them $20-600 \mathrm{~nm}$ in size, specific surfaces of up $338 \mathrm{~m}^{2} / \mathrm{g}$, productivity of up to $12 \mathrm{~g} / \mathrm{h}$, and a specific power consumption $\geq 112(\mathrm{~W} \mathrm{~h}) / \mathrm{g}$.
\end{abstract}

\section{Introduction}

Production of weak aggregated nanopowders (NPs) with the characteristic size in the field of less than $10 \mathrm{~nm}$ and narrow distribution of particles in the sizes remains is an actual problem, especially, for complex chemical compounds at high cleanliness of a received product. Thus it is desirable, that the method provided the possibility to use as raw materials enough cheap substances and probably wider range of it (conducting and nonconducting, alloys and metals, mechanical mixes, etc.).

For many problems ways of producing NPs by a method of pulse heating and target evaporation passing a pulsed current-electric explosion of wire (EEW) [1] and pulsed $\mathrm{CO}_{2}$ laser irradiation [2] is successfully used. EEW allows us to produce NP metals and alloys, and also their chemical compounds at rather small consumed energy $(<50 \mathrm{Wh} / \mathrm{g})$ and high efficiency $(50-400 \mathrm{~g} / \mathrm{h})$. However, produced NPs have rather wide size distribution of particles and it is not possible to prepare all desirable metals and alloys in the form of a metal wire of certain diameter and structure.
For production of NP by target evaporation irradiation of various types of lasers is used, but the greatest application have found $\mathrm{CO}_{2}$ [2] and fiber lasers [3]. Using of the continual $\mathrm{CO}_{2}$ laser, it has been shown $[4,5]$ that productivity of process depends on capacity of radiation and its intensity, productivity reaches $130 \mathrm{~g} / \mathrm{h}$ at consumed energy $25 \mathrm{Wh} / \mathrm{g}$, and the size of particles $d_{\mathrm{BET}}=60 \mathrm{~nm}$ for $\mathrm{ZrO}_{2}$ powders.

The pulse mode should provide reduction of the size of particles, at invariable consumption of energy, at the expense of the best removal of particles from a hot zone and faster decrease in concentration of steams, and also possibility of increase intensity of radiation. For realization of a pulse mode of evaporation was used pulse $\mathrm{CO}_{2}[5,6]$ which allows to reduce essentially width of distribution of received particles till the size, and also to use as raw materials for targets cheap large powders. At equal power consumption, in comparison with the continual $\mathrm{CO}_{2}$ laser, use of pulse irradiation has allowed to lower the characteristic size of particles from 4 to 6 times. It was experimentally shown that the major factor defining productivity of installation with set characteristics, was specific energy of evaporation of 
a material. It is important to notice that the method provides preparation of pure NPs and is ecologically pure.

However, this method has small efficiency (1-2\%) in the use of energy because of its losses at radiation generation, and also at interaction of radiation with a plasma jet and substance. Productivity of a method was from 15 to $80 \mathrm{~g} / \mathrm{h}$ and, basically, was defined by the energy which is required for evaporation powders of chosen structure. The basic problems connected with insufficient efficiency and small operating time $\mathrm{CO}_{2}$-laser was eliminated at transition to fiber lasers [7].

In our point of view to increase the efficiency of energy transformation in radiation and use the irradiation for the evaporation, heating a target by an electron beam looks more attractive. Unlike laser radiation, using the electron beam, being formed on a target surface plasma absorbs arriving energy of the beam according to density of steam of target material. Thus, target heating under a vapour-plasma jet proceeds, though and with slightly smaller capacity. At use of accelerators with high electron energy $(>1 \mathrm{MeV})$ to evaporation of targets in high-pressure gas that simplifies questions of cooling of a steam phase and collection of the formed powder [8] was possible. But such accelerators with necessary radiating shield are expensive enough.

Electron guns with energy to $50 \mathrm{keV}$ are rather cheaper; however in this case the beam injection to atmosphere is impossible. The available literary data on use of such guns with continuous beam [9-11] for production NPs simple oxides at low pressure of gas has shown that in all researches powders oxides with the size of particles less than $5 \mathrm{~nm}$ were produced. However in work [9] the particles was poorly agglomerated and consumed energy was $200 \mathrm{~W} \mathrm{~h} / \mathrm{g}$ for $\mathrm{Al}_{2} \mathrm{O}_{3}$ whereas in $[10,11]$ powders only in the form of agglomerates of particles were produced, and consumed energy have increased to 1000 [10] W h/g and more $4000 \mathrm{~W} \mathrm{h/g} \mathrm{[11].}$

These contradictions, desire to lower an energy expense and also to investigate production possibilities of NPs with complex structures stimulated us to create the installation with a pulsed electron gun and to the beginning of experiments in this direction.

It is necessary to consider that at heating by an electron beam excluding the creation of a liquid bath completely was impossible, as absorption of energy of an electron beam has nonlinear distribution [12]. Expansion in gas of low pressure allows receiving high speeds of decrease in concentration of steams that promotes production of small sizes particle, but speed of cooling of steams and particles that allow their aggregation simultaneously falls. A doubtless advantage of pulsed electron beam (PEB) is that it is possible rather simply to change, except electrons energy, a pulse width and repetition rate that expands experimental possibilities. Besides, to operate position of PEB it is simple enough at the expense of its scanning that facilitates a problem of uniform evaporation of a target, in difference from lasers.

The first installation "Nanobim-1" for production nanopowder by a method of PEB evaporation of target [13], using a hollow cathode gun [14], with condensation of steams of a material in low-pressure gas and condensation NPs on a cold crystallizer, has been placed in KAERI
(Republic Korea) and has shown a realizability and certain advantages and disadvantages of the method [13]. The received experience has allowed us to create the modernized installation "Nanobeam-2" using which various NPs have been received and their properties were investigated.

\section{The Description of Installation and Experiments Conditions}

Installation diagram of the "Nanobeam-2" is given in Figure 1, and its technical characteristics are in Table 1. For normal work of the chosen electron gun pressure about $10^{-2} \mathrm{~Pa}$ is required, and for fast cooling of particles it is desirable to have a high pressure in the evaporation chamber. Calculations on [15] for the chosen geometry of the chamber of drift (length $20 \mathrm{~cm}$ ), have shown that at reasonable losses of energy of a beam (not more than 10\%) in the chamber of drift the pressure size in the evaporation chamber can be $100 \mathrm{~Pa}$.

These inconsistent requirements are provided with pumping out from three zones divided two gaz-dynamic windows [17] with apertures in diameter of 3,2 $\mathrm{mm}, 100 \mathrm{~mm}$ placed on distance from each other in the drift chamber where focusing and rejecting coils are located also.

Pumping out of air from chambers of an electron gun and drift was carried out by diffusion pumps by productivity 160 and 1001/sec, accordingly, and from the evaporation chamber-mechanical pump productivity $60 \mathrm{l} / \mathrm{sec}$.

All chambers were made of stainless steel, by sheet lead in the thickness of $5 \mathrm{~mm}$ for X-ray radiation shield are outside covered, viewing windows were protected by lead glass in the thickness of $20 \mathrm{~mm}$.

Operating experience of installation "Nanobeam" has shown that the electron gun [14] forms insufficient amplitude of a current and demanded energy was necessary to type at the expense of increase of pulse width that raised losses of energy at the expense of heat conductivity. Therefore the new design of an electron gun with the plasma emitter which generates a pulse electron beam with frequency of repetition of $1-500 \mathrm{~Hz}$ and duration of impulses of a current $100 \mu \mathrm{sec}$, at accelerating voltage up to $40 \kappa \mathrm{V}$ with a current about $1 \mathrm{~A}$ [18] has been created.

Beam scanning on a target is carried out continuously by a principle of development of a TV camera, thus the scanning area could change from 0,8 to $4 \mathrm{~cm}^{2}$.

Target (a tablet in diameter of $40-60 \mathrm{~mm}$ and height to $20 \mathrm{~mm}$, Figure 2) it is established in a support having free rotation (with fixing) in two axes.

At an adjustment and focusing electron beam the target is established horizontally. For evaporation the target turns at an angle $45^{\circ}$ to the beam in the crystallizer direction for increase in collecting the powder. The support design allowed to rotate a target with speed of 8,7 turns/min, for its more uniform evaporation, and also to replace it from a cut of the rejecting coil in limits from 80 to $170 \mathrm{~mm}$.

Used in [13] the powder collection system on the basis of a rotating cooled hollow disk it has appeared difficult in operation. Besides, at increase in distance from a target 


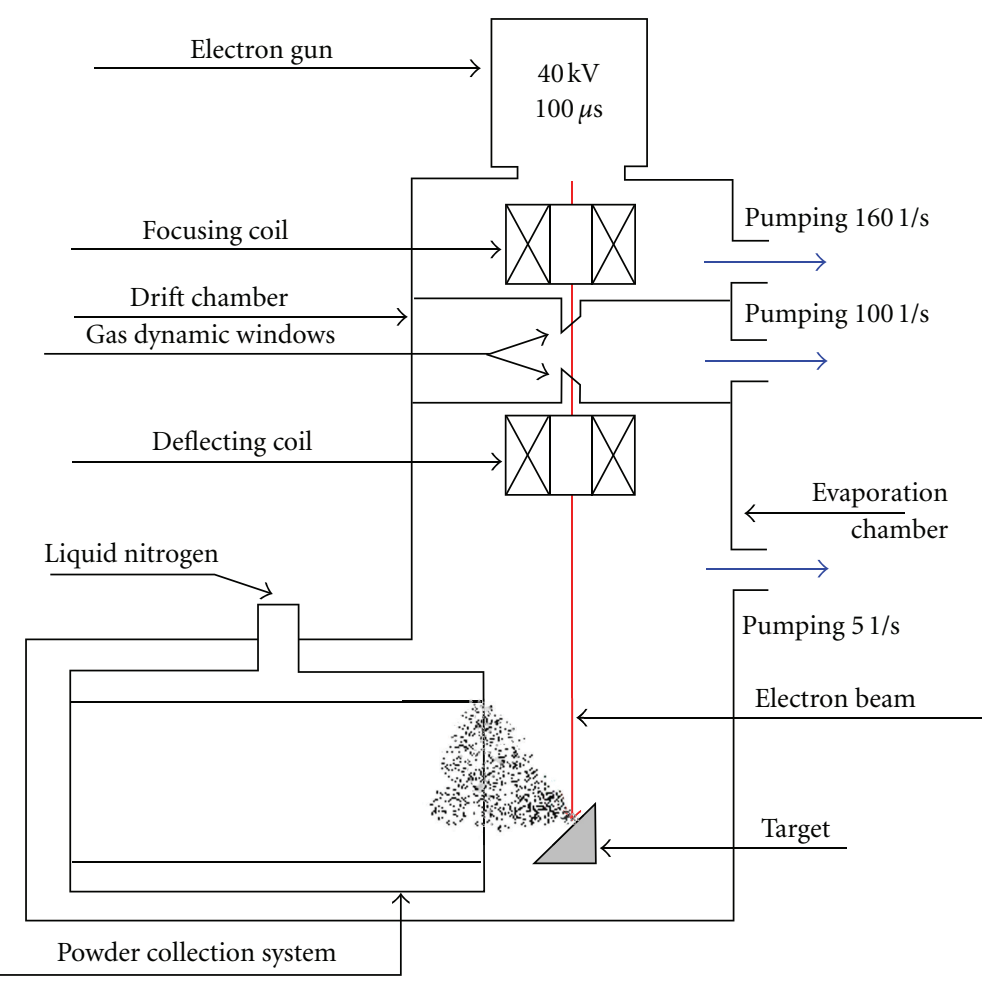

Figure 1: Installation diagram of the "Nanobeam-2" (program Paint).

TABLE 1: Installation characteristics of the "Nanobeam 2".

\begin{tabular}{llc}
\hline No. & Characteristics & Value \\
\hline 1 & Power consumption, $\kappa$ VA, no more than & 5 \\
2 & Power supply & $380 \mathrm{~V}(3 \mathrm{ph}),. 50 \mathrm{~Hz}$ \\
3 & Pulse width, $\mu$ s & $50-100$ \\
4 & Pulse repetition rate, pps & up to 500 \\
5 & Accelerating voltage, $\mathrm{kV}$ & up to 40 \\
6 & Beam current on a target, A & 0,46 \\
7 & Beam diameter on a targets, mm & 1,5 \\
8 & Pressure limits of regulation in the evaporation chamber, Pa & $10-1-105$ \\
9 & Inleakage gas speed to the the evaporation chamber, $1 /$ hour & to 63 \\
10 & Weights of installation, kg, no more than & 700 \\
11 & Area of placing of installation, m*m & $3 * 3$ \\
\hline
\end{tabular}

the share of a collected powder essentially decreases to a disk for the geometrical reasons. The modernized powder collection system is executed on the basis of the hollow copper cylinder, with internal diameter $300 \mathrm{~mm}$ which is established perpendicularly to a beam axis, on distance of $7 \mathrm{~mm}$ from target edge. The cylinder is cooled from within by liquid nitrogen with the expense about $5 \mathrm{~kg} /$ hour. From the cylinder the powder collected manually using a scraper. For simplification the technology of collection and control of doping NPs the cylinder surface can be covered by sheet from other metal (usually stainless steel).

The following methods were used for examination of the materials.
(1) The specific surface of the powders $S_{\text {BETs }}$ was measured by the BET method on a TriStar 3000 V6.03 analyzer.

(2) The chemical composition of the powders was determined and the X-ray diffraction analysis (XRD) was performed using standard methods on a Discover D8 $\mathrm{X}$-ray diffractometer.

(3) The microscopic analysis was made in electronic microscopes SEM LEO-982 and TEM JEOL 2100.

Phase transformations, the concentration, and the absorption of gases in the powders were determined by the methods of scanning differential calorimetry (DSC) and thermogravimetric analysis (TG) on an STA 409 PC Luxx 


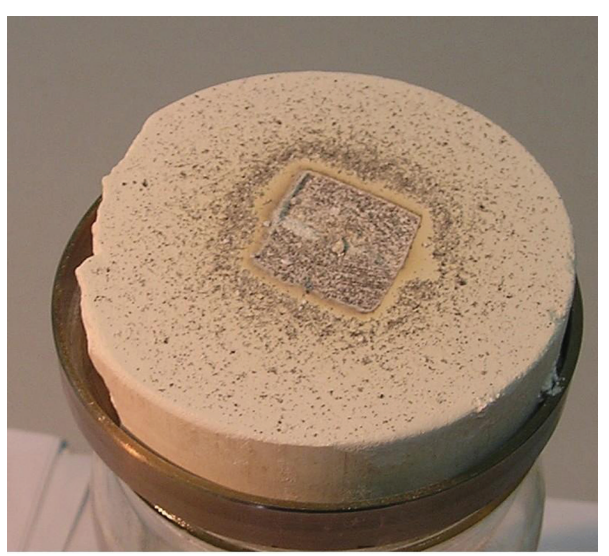

(a)

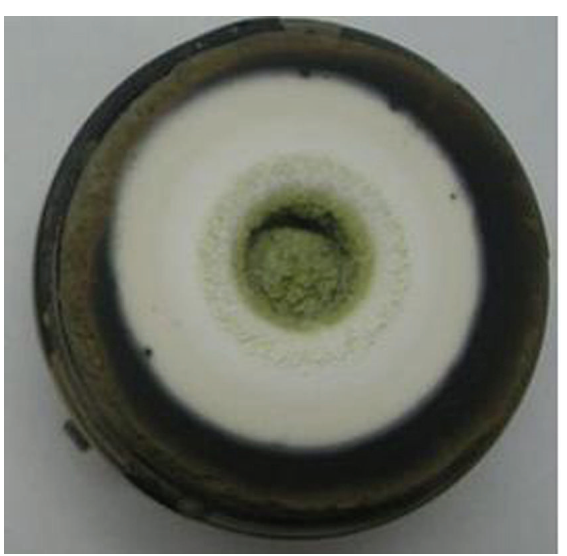

(b)

FIGURE 2: Photos of the target from YSZ the beam print and large particles (without rotation—at the left) and the crater formed in the target from $\mathrm{ZnO}$ at rotation.

thermal analyzer and a QMS 403 C Aëolos mass spectrometer (NETZSCH).

The chemical analysis were carried out by the method of inductive and connected plasma (ICP) on the spectrometer iCAP 6300 Duo.

Magnetic characteristics NPs defined on the scales of Faraday.

The accelerating voltage of $37-40 \mathrm{kV}$ was used in the experiments. Upon transportation and focusing the beam current on the target was not less than $0.46 \mathrm{~A}$ at the beam diameter of about $1.0 \mathrm{~mm}$, providing the power density (the intensity) of about $10^{6} \mathrm{~W} / \mathrm{cm}^{2}$.

The pressure of the evaporation chamber was adjusted between 3.8 and $50 \mathrm{~Pa}$. The beam energy loss caused by this adjustment was several percent and was disregarded. Air, oxygen, and argon were used in the experiments and the gas inleakage rate was controlled by rotameters.

The total current of the electron beam and the beam current hitting the target were measured by current transformers installed in the accelerating voltage source and on the target support acting as a current lead. The shunt in the connection between the upper gas dynamic window and the casing allowed measuring the proportion of the current lost as the beam was transported through the window.

The operating principle of the device is as follows. The electron beam is focused at the hole of the upper gas dynamic window and, as it passes through the second gas dynamic window, it focused additionally on the deflecting coil. This coil also sweeps the beam on the target. The material of the target evaporates under the action of the beam; the vapor-plasma mixture is cooled by the low-pressure gas in the evaporation chamber; and the vapor condenses with the formation of nanopowder particles. The powder flies to the cooled crystallizer and is deposited thereon.

\section{Results of Experiments}

Installation characteristics were defined in experiments on production of powders various oxides. Targets were carried out from industrial powders of demanded oxides in the micron sizes, pure and with various alloying additives, by the method of manual pressing with the subsequent roasting, for receiving ceramics, because not annealed targets collapsed from influence of IEP and did not allow to receive NPs with the high specific surface $S_{\mathrm{BET}}$.

The synthesized YSZ (zirconia stabilized with 10 molar $\%$ of yttria) powders had a large-specific surface and were agglomerated to complexes of 20 to $600 \mathrm{~nm}$ in size, which consisted of particles with a sufficiently narrow size distribution of about several nm (Figure 3). The specific surface of the synthesized YSZ powders could be as large as $S_{\mathrm{BET}}=250 \mathrm{~m}^{2} / \mathrm{g}$ and after sedimentation to $S_{\mathrm{BET}}=270 \mathrm{~m}^{2} / \mathrm{g}$.

$\mathrm{XRD}$ of the synthesized powder showed that the sample had two phases.

(i) The first phase was a solid solution of $\mathrm{Y}_{2} \mathrm{O}_{3}$ in the cubic modification of $\mathrm{ZrO}_{2}$. The lattice spacing $a=5.148 \AA$ and the coherent scattering regions (CSR) were $130 \mathrm{~nm}$ in size. The $\mathrm{Y}_{2} \mathrm{O}_{3}$ concentration was $\approx 11$ mole $\%$. The varying concentration of yttria suggested that the phase was not fragments of the target, but represented a synthesis product. The concentration of this phase was $\approx 7$ weight $\%$.

(ii) The second phase ( $\approx 93$ weight $\%)$ was an $\mathrm{X}$ ray amorphous phase with the short-range order characteristic of the monoclinic form of zirconia having the following parameters: $a=5.17 \AA, b=$ $5.10 \AA, c=5.44 \AA$, and $\beta=86.9^{\circ}$. The $\mathrm{CSR}$ was $1 \div$ $2 \AA$ in size on the average.

The obtained result is nontrivial. Earlier investigations into synthesis of zirconia nanopowders (our data and the literature $[19,20])$ showed that the tetragonal and cubic phases, which are most metastable at room temperature, are stabilized with decreasing size of the particles. In this experiment the finest phase is the monoclinic one, that is, the most stable phase. This would not be so if pure zirconia is synthesized. We synthesized yttrium-stabilized $\mathrm{ZrO}_{2}$. 


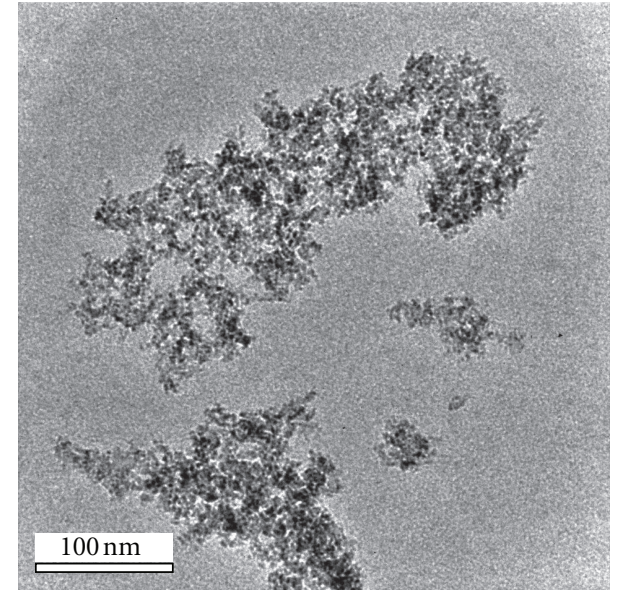

Figure 3: TEM photographs of 10YSZ powders.

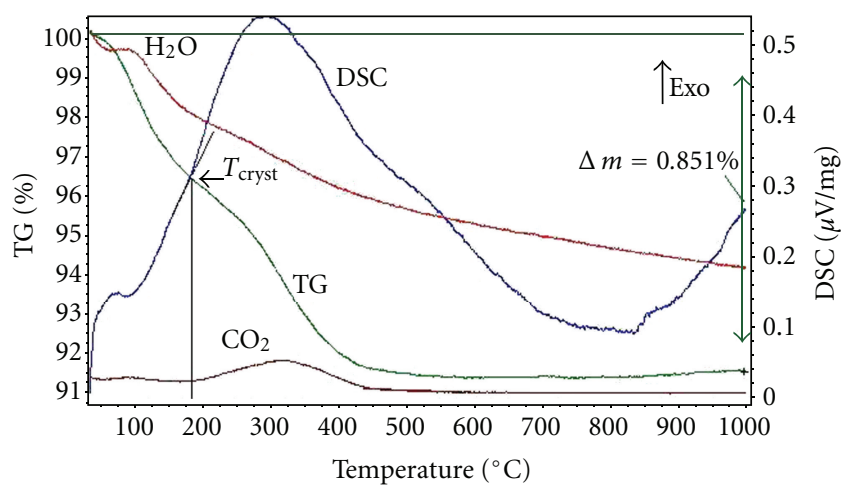

FIGURE 4: TG-DSC curves of the sample YSZ besieged on the copper crystallizer and cooled by liquid nitrogen (program Paint).

The stable phase for this compound is the cubic modification. The most metastable is the monoclinic phase and, naturally, it is this phase that forms in finest particles. For understanding of real distribution of a yttrium on particles depending on their size of research it is necessary to continue.

Results TG-DSC of the analysis have shown (Figure 4) that at temperature nearby $187^{\circ} \mathrm{C}$ on curve DSC is observed strong exothermic peak caused by crystallization of a X-ray amorphous phase.

Under the literary data amorphous oxide $\mathrm{ZrO}_{2}$ crystallizes at temperature $393^{\circ} \mathrm{C}, \mathrm{Y}_{2} \mathrm{O}_{3}$ is the effective stabilizer of amorphous condition $\mathrm{ZrO}_{2}$ and leads to rise in temperature of crystallization of amorphous solid solution $\mathrm{Zr}_{0.95} \mathrm{Y}_{0,05} \mathrm{O}_{1,975}$ to $407-442^{\circ} \mathrm{C}$ [21]. However, in work [22] temperature of crystallization amorphous zirconia received by thermal decomposition of a carbonate has made $350^{\circ} \mathrm{C}$. In our case there was a decrease in temperature of crystallization concerning known [21] almost on $220^{\circ} \mathrm{C}$ that unequivocally specifies in essential influence of the dimensional factor on temperature of crystallization X-ray amorphous components as the average size of crystalline particles in it is considerable below (1-2 nm), than at amorphous $\mathrm{ZrO}_{2}$ in work [22].

We experimentally found for the first time a ferromagnetic condition at room temperature in NPS YSZ [16]. From

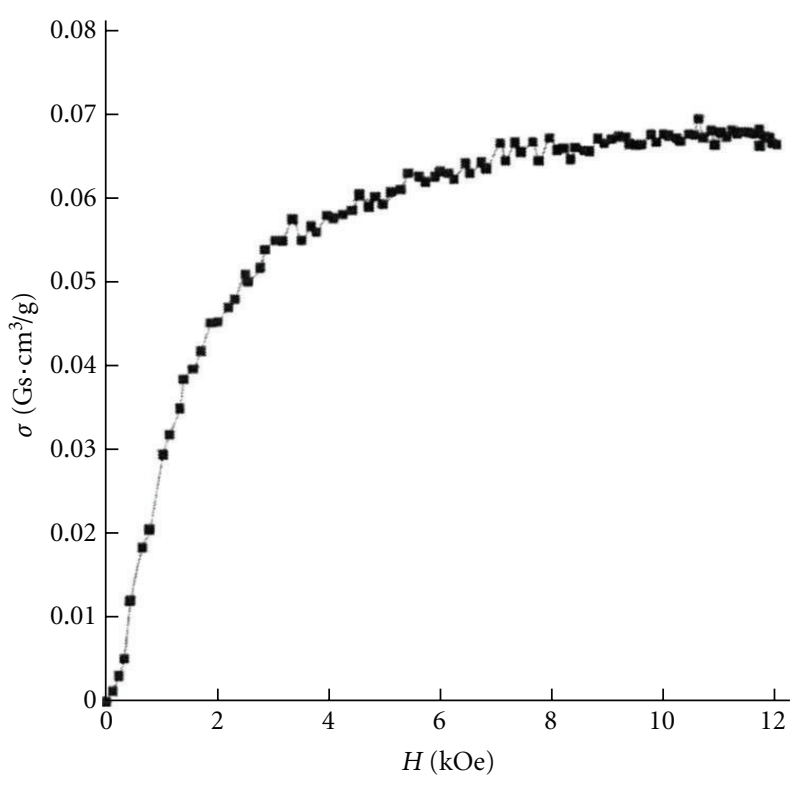

FIGURE 5: Magnetization of the sample YSZ at room temperature [16] (program Paint).

the data Figure 5 it is visible that magnetization of saturation NPS YSZ makes 0,067 emu/g.

Almost at the same time with us, in the review [23] were provided magnetic characteristics of thin films of YSZ to room temperature $\left(3,5 \times 10^{-7} \mathrm{emu} / \mathrm{g}\right)$, this is on 5 orders lower than size of magnetization of NP YSZ established by us. Recently, one more experimental confirmation of a ferromagnetism of $\mathrm{ZrO}_{2}$ is given in C. N. R. Rao work [24]. Ferromagnetism is found out in nanoparticles tetragonal phase $\mathrm{ZrO}_{2}$ with the sizes $5-8 \mathrm{~nm}$ at temperatures 673 and $873 \mathrm{~K}\left(3,97 \times 10^{-3}\right.$ and $1,93 \times 10^{-3} \mathrm{emu} / \mathrm{g}$, accordingly $)$, received by hydrolysis $\mathrm{ZrOCl}_{2}$ at a microwave irradiation in water solution $\mathrm{NaOH}$.

The experiments with gadolinium-doped ceria confirmed the earlier results and demonstrated the possibility of producing powders with $S_{s}$ of about $190 \mathrm{~m}^{2} / \mathrm{g}$. The synthesized powders had a large-specific surface and were agglomerated to complexes 20 to $600 \mathrm{~nm}$ in size similar to those of YSZ (Figure 6).

The X-ray diffraction analysis showed that two phases, a mechanical mixture of $\mathrm{CeO}_{2}$ and $\mathrm{Gd}_{2} \mathrm{O}_{3}$, were present in the material of the target. Given below are characteristics of their structures.

(i) $\mathrm{CeO}_{2}$ : a cubic lattice of the fluorite type with the spacing $a=5.413 \AA$; the CSR $84 \mathrm{~nm}$ in size; and the concentration of $\approx 81$ weight $\%$;

(ii) $\mathrm{Gd}_{2} \mathrm{O}_{3}$ : a cubic lattice of the $\mathrm{Mn}_{2} \mathrm{O}_{3}$ type with the spacing $a=10.89 \AA$; the CSR $124 \mathrm{~nm}$ in size; and the concentration of $\approx 18$ weight $\%$.

Remarkably, the value of the lattice spacing of the phase at hand is considerably different from the corresponding

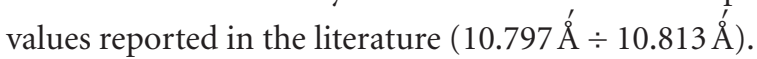




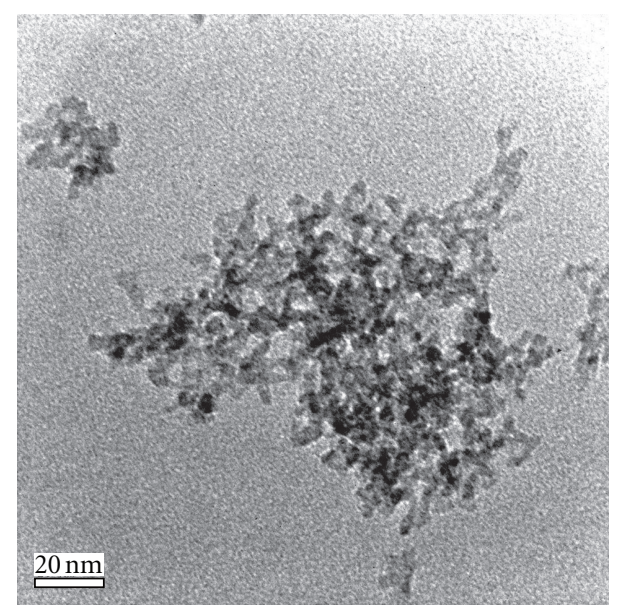

Figure 6: TEM photographs of $\mathrm{Ce}_{1-x} \mathrm{Gd}_{x} \mathrm{O}_{2-\delta}$ powders.

According to the analysis, the material is complicated and does not lend itself to an unambiguous interpretation. A model of one phase-a solid solution of gadolinium in $\mathrm{CeO}_{2}$-is considered as a first approximation. Figure 8 shows parameters of the diffraction pattern as refined by the method of full-profile analysis. The following characteristics of the structure were determined: the lattice spacing $a=$ $5.431 \AA$ and the CSR size equal to $3.7 \mathrm{~nm}$. It should be noted however that the estimated spacing corresponded to the $\mathrm{Gd}_{2} \mathrm{O}_{3}$ concentration equal to or larger than 20 mole $\%$ (this value already corresponds to the two-phase region of the concentrations). Furthermore, the sharp fragments of the diffraction peaks, which are seen in the diffraction pattern, are not described by the Lorentz function, which is typical of dispersed powders. Therefore, a more complex model needs be considered.

A model of two phases was considered as a first approximation.

(1) A solid solution of cerium in the cubic lattice of $\mathrm{Gd}_{2} \mathrm{O}_{3}$, a fine crystalline phase.

(2) A solid solution of gadolinium in the cubic lattice of $\mathrm{CeO}_{2}$, a coarse crystalline phase.

Results of the refinement procedure are given in Figure 7. The following characteristics of the structure were determined.

(i) A solid solution of cerium in the cubic lattice of $\mathrm{Gd}_{2} \mathrm{O}_{3}$ : the spacing $a=10.88 \AA$; CSR $3 \mathrm{~nm}$ in size; the concentration of $\approx 97$ weight $\%$.

(ii) A solid solution of gadolinium in the cubic lattice of $\mathrm{CeO}_{2}$ : the spacing $a=5.415 \AA$; CSR $\approx 60 \mathrm{~nm}$ in size; and the concentration of $\approx 3$ weight $\%$.

Thus, the X-ray diffraction analysis demonstrated that the two-phase nanopowder, which was synthesized in the cerium-gadolinium system, can be interpreted as resulting from an incomplete reaction (a mechanical mixture was the initial material). This interpretation does not apply to the zirconium-yttrium system (one phase was present in the

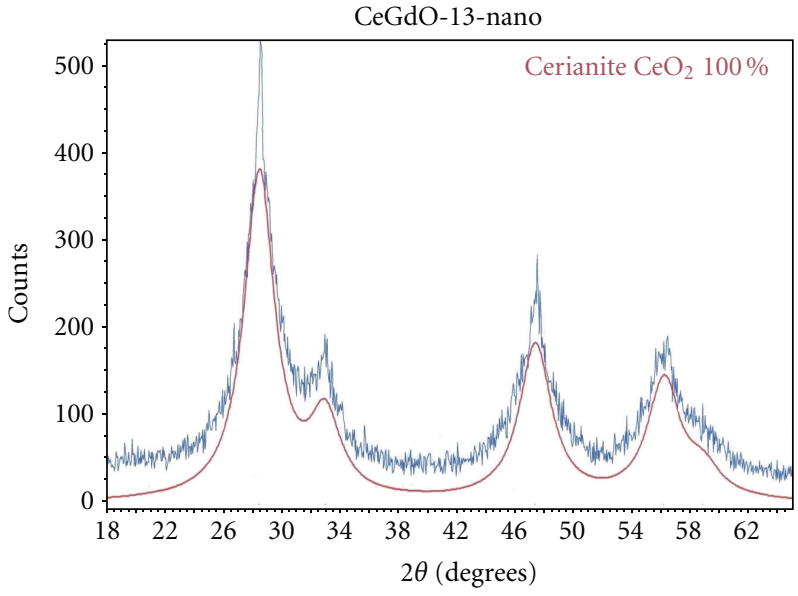

Figure 7: Diffraction pattern of the nanopowder $\mathrm{Ce}_{1-x} \mathrm{Gd}_{x} \mathrm{O}_{2-\delta}$ (program Paint).

initial material). The insynthesis formation of two phases, which differ by the CSR size and the chemical composition, is of principal significance and is connected with the synthesis method used.

Using installation Nanobeam-2 were synthesized new Xray contrast substance (XRCS), consisting of difficult oxides tantalum and rare-earth elements $\left(\mathrm{LaTaO}_{4}\right.$ and $\left.\mathrm{YTaO}_{4}[25]\right)$, and their comparison with the same of materials in a microsize $\left(S_{\mathrm{BET}} \sim 0,04 \mathrm{~m}^{2} / \mathrm{g}\right)$ has been executed. Received NP had $S_{\text {BET }} \sim 165-185 \mathrm{~m}^{2} / \mathrm{g}$. According to PEM VR are received poorly agglomerated NP consisting of units, formed crystal LF in the size of $\sim 3-5$ nanometers, with very narrow distribution of particles on the size which in turn form agglomerates in the size to several hundred nanometers. At all NP there are large particles of the micron size. Compared XRCS in 5 wt. \% water suspension were placed in glass bottles in capacity of $10 \mathrm{~mL}$ and irradiated using the RUM-20 M Xray device. For dose measurement the X-ray film was used on usual technology. Density of dimness was measured on MD-100 microdensitometer.

It is established that X-rays contrast of images of the bottles containing nanoslips above, than the bottles containing suspensions with micropowders on $20-30 \%$. Thus, it was found that X-rays contrast of XRCS depends not only from chemical, but also granulometric structures of substances [25].

At production nanopowder $\mathrm{Al}_{2} \mathrm{O}_{3}$ and $\mathrm{Al}_{2} \mathrm{O}_{3}-\mathrm{Cu}(\mathrm{Al})$ in vacuum was found that with increase in concentration of copper in NPS $\mathrm{Al}_{2} \mathrm{O}_{3}-\mathrm{Cu}$ the size of a specific surface decreases (Table 2). The greatest $S_{\mathrm{BET}}$ is received for weak doped $\mathrm{NP} \mathrm{Al}_{2} \mathrm{O}_{3}-1,7 \mathrm{wt} \% \mathrm{Cu}$, thus its size is close to record indicators for NPS pure $\mathrm{Al}_{2} \mathrm{O}_{3}\left(340 \mathrm{~m}^{2} / \mathrm{g}\right.$ [9], $320 \mathrm{~m}^{2} / \mathrm{g}$ [26]).

$\mathrm{XRD}$ it is established (Table 3 ) that NPs contain on three crystal phases: $\alpha-\mathrm{Al}_{2} \mathrm{O}_{3}$ (corundum), $\gamma-\mathrm{Al}_{2} \mathrm{O}_{3}$ (cubic), and $\theta-\mathrm{Al}_{2} \mathrm{O}_{3}$ (monoclinic) phases. In NPs, doped $\mathrm{Cu}$, was found out crystal soured copper. At all NPs is present as well the amorphous component. In Table 4 values of the periods of crystal lattices of the revealed phases are resulted. 


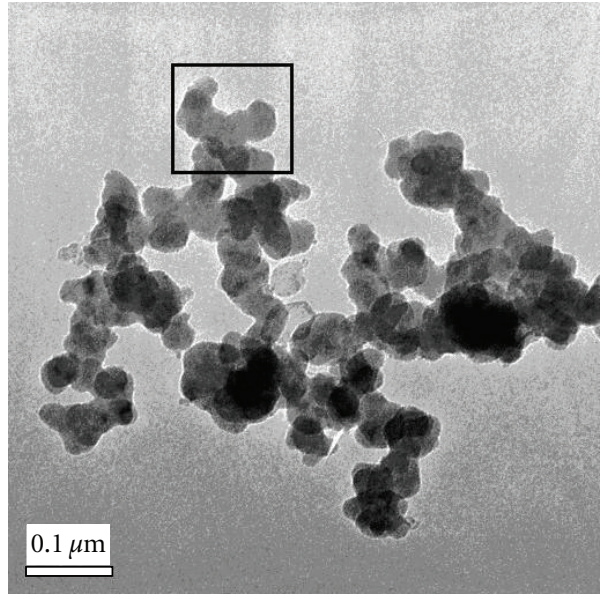

(a)

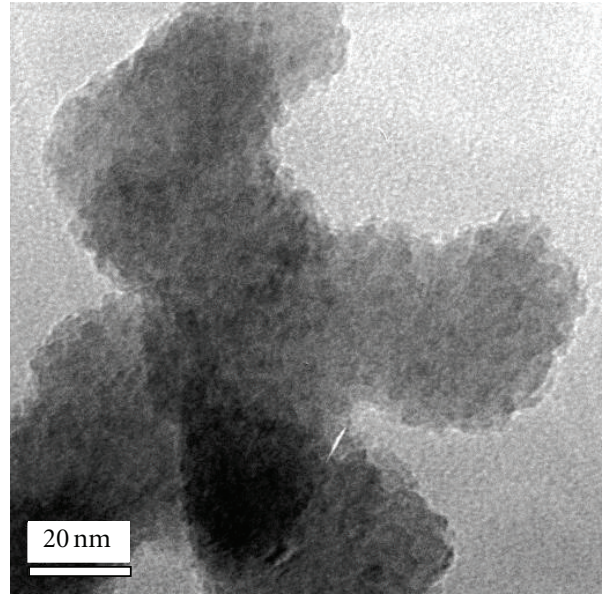

(b)

Figure 8: (a) Chains of particles (NPS $\mathrm{Al}_{2} \mathrm{O}_{3}-1,7$ wt. \% Cu); (b) aggregates of particles about $5 \mathrm{~nm}$ in size $\left(\mathrm{NPS}^{\mathrm{A}} \mathrm{O}_{2} \mathrm{O}_{3}-1,7 \mathrm{wt}\right.$. \% Cu).

TABLE 2: Specific surface NPS $\mathrm{Al}_{2} \mathrm{O}_{3}$ and $\mathrm{Al}_{2} \mathrm{O}_{3}-\mathrm{Al}(\mathrm{Cu})$.

\begin{tabular}{lccccc}
\hline Composition NPs (PEB) & $\mathrm{Al}_{2} \mathrm{O}_{3}$ & $\mathrm{Al}_{2} \mathrm{O}_{3}-\mathrm{Al}$ & $\mathrm{Al}_{2} \mathrm{O}_{3}-1,7 \% \mathrm{Cu}$ & $\mathrm{Al}_{2} \mathrm{O}_{3}-11,2 \% \mathrm{Cu}$ & $\mathrm{Al}_{2} \mathrm{O}_{3}-17,2 \mathrm{Cu}$ \\
\hline$S_{\mathrm{BET}}, \mathrm{m}^{2} / \mathrm{g}$ & 269,69 & 197,80 & 338,25 & 80,71 & 68,71 \\
\hline
\end{tabular}

TABLE 3: Relative concentrations of the crystalline phases and average values of CSR.

\begin{tabular}{|c|c|c|c|c|c|c|c|}
\hline \multirow{2}{*}{ Composition NPs (wt \% Cu) } & \multicolumn{2}{|c|}{$\alpha-\mathrm{Al}_{2} \mathrm{O}_{3}$ (Corundum) } & \multicolumn{2}{|c|}{$\gamma-\mathrm{Al}_{2} \mathrm{O}_{3}$ (cubic) } & \multicolumn{2}{|c|}{$\theta-\mathrm{Al}_{2} \mathrm{O}_{3}$ (monoclinic) } & \multirow{2}{*}{$\mathrm{Cu}_{2} \mathrm{O}$} \\
\hline & Concentration, wt \% & $\mathrm{CSR}, \mathrm{nm}$ & Concentration, wt \% & CSR, nm & Concentration, wt \% & $\mathrm{CSR}, \mathrm{nm}$ & \\
\hline $\mathrm{Al}_{2} \mathrm{O}_{3}$ & $65(3)$ & $78(2)$ & $24(3)$ & $21(2)$ & $11(3)$ & $\approx 30$ & \\
\hline $\mathrm{Al}_{2} \mathrm{O}_{3}-\mathrm{Al}$ & $64(3)$ & $68(2)$ & $25(3)$ & $26(2)$ & $11(3)$ & $\approx 40$ & \\
\hline $\mathrm{Al}_{2} \mathrm{O}_{3}(1,72)$ & $28(3)$ & $75(3)$ & $45(3)$ & $32(2)$ & $27(3)$ & $\approx 20$ & - \\
\hline $\mathrm{Al}_{2} \mathrm{O}_{3}(11,19)$ & 60 & 45 & 23 & 28 & 15 & $\approx 25$ & 2 \\
\hline $\mathrm{Al}_{2} \mathrm{O}_{3}(17,22)$ & 55 & 43 & 26 & 28 & 16 & $\approx 25$ & 3 \\
\hline
\end{tabular}

TABLE 4: Lattice spacing of the phases in $\mathrm{Al}_{2} \mathrm{O}_{3}-\mathrm{Al}(\mathrm{Cu})$ NPs.

\begin{tabular}{|c|c|c|c|c|c|c|c|}
\hline \multirow{2}{*}{ Sample (wt \% Cu) } & \multicolumn{2}{|c|}{$\alpha-\mathrm{Al}_{2} \mathrm{O}_{3}$} & \multirow{2}{*}{$\begin{array}{c}\gamma-\mathrm{Al}_{2} \mathrm{O}_{3} \\
a, \AA\end{array}$} & \multicolumn{4}{|c|}{$\theta-\mathrm{Al}_{2} \mathrm{O}_{3}$} \\
\hline & $a, \AA ́$ & $c, \AA ̊$ & & $a, \AA$ & $b, \AA ̊$ & 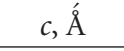 & в, град \\
\hline $\mathrm{Al}_{2} \mathrm{O}_{3}$ & $4,761(2)^{*}$ & $13,003(5)$ & $7,918(4)$ & $11,83(7)$ & $2,92(1)$ & $5,63(2)$ & $103,9(1)$ \\
\hline $\mathrm{Al}_{2} \mathrm{O}_{3}-\mathrm{Al}$ & $4,759(2)$ & $12,993(5)$ & $7,905(4)$ & $11,84(7)$ & $2,91(1)$ & $5,61(2)$ & $103,8(1)$ \\
\hline $\mathrm{Al}_{2} \mathrm{O}_{3}(1,72)$ & $4,759(2)$ & $12,987(5)$ & $7,909(4)$ & $11,96(7)$ & $2,92(1)$ & $5,58(2)$ & $103,8(1)$ \\
\hline $\mathrm{Al}_{2} \mathrm{O}_{3}(11,19)$ & $4,770(5)$ & $12,997(7)$ & $7,914(6)$ & $11,87(7)$ & $2,91(1)$ & $5,62(1)$ & $103,8(1)$ \\
\hline $\mathrm{Al}_{2} \mathrm{O}_{3}(17,22)$ & $4,761(5)$ & $13,024(7)$ & $7,930(4)$ & $11,88(7)$ & $2,92(1)$ & $5,63(1)$ & $103,8(1)$ \\
\hline Literary data from file PDF-2 & 4,7587 & 12,9929 & 7,939 & 11,813 & 2,906 & 5,625 & 104,1 \\
\hline PDF-2 card \# & \multicolumn{2}{|c|}{ 00-046-1212 } & 00-050-0741 & \multicolumn{4}{|c|}{ 00-023-1009 } \\
\hline
\end{tabular}

${ }^{*}$ In brackets is an absolute error of measurement XRD.

Thus the strongest changes was observed for lowtemperature metastable $\gamma$-phases. On absolute size the periods of a lattice scale of a phase much less than their known values under the literature, the least correspond not doped or doped aluminum to a case. It is not surprisingsynthesis passed in vacuum conditions, hence, naturally to expect presence in a material of a considerable quantity of oxygen vacancies.
The general in morphology of samples $\mathrm{Al}_{2} \mathrm{O}_{3}-\mathrm{Al}(\mathrm{Cu})$ consists in the following.

(1) Large shapeless and spherical particles in the size up to 10 micron, most likely it is target splinters.

(2) Shapeless amorphous particles in the size from $40 \mathrm{~nm}$ to 1 micron at which the picture of electronic 


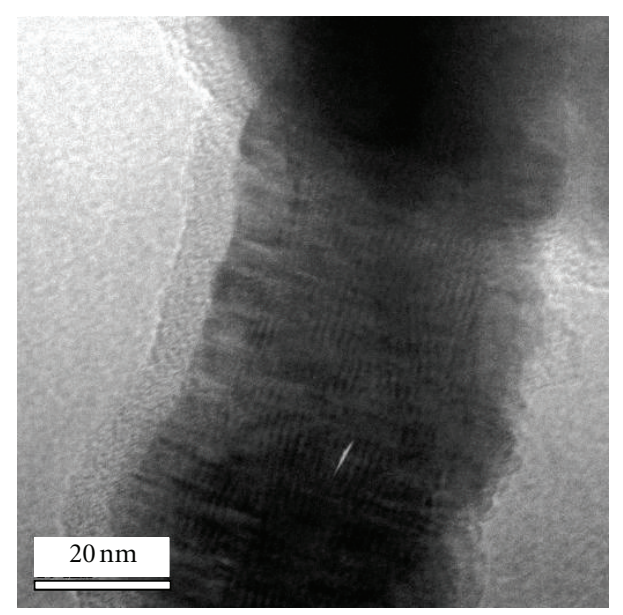

FIGURE 9: Nanocrystalline particle in an amorphous shell (NPS $\mathrm{Al}_{2} \mathrm{O}_{3}-1,7$ wt. \% Cu).

diffraction of the allocated area represents characteristic halo.

(3) Chains of particles in the size of $50-70 \mathrm{~nm}$, each of which represents agglomerates from particles in the size about $5 \mathrm{~nm}$ (Figure 8) with very narrow distribution of particles on the size.

(4) The crystalline particles covered with an amorphous layer in the thickness from 2 to $10 \mathrm{~nm}$ (Figure 9).

(5) TEM with the nuclear permission were received only at samples $\mathrm{Al}_{2} \mathrm{O}_{3}-\mathrm{Cu}$, and at samples $\mathrm{Al}_{2} \mathrm{O}_{3}-\mathrm{Al}$; it has not turned out, because of presence on a surface of an amorphous layer.

Room-temperature ferromagnetism has been observed in $\mathrm{Cu}, \mathrm{Al}$-doped $\mathrm{Al}_{2} \mathrm{O}_{3}$. As a whole the level of magnetization $\mathrm{Al}_{2} \mathrm{O}_{3}-\mathrm{Cu}$ NPs were in ten times more than the level of magnetization $\mathrm{Al}_{2} \mathrm{O}_{3}$ NPs fabricated by thermal heating of aluminum hydroxide [27]. Most likely it is connected with presence of magnetic ions $\mathrm{Cu}^{2+}$, and also the big defective structure of NPs, formed as a result of evaporation PEB, than at a chemical method [27]. At increase in concentration $\mathrm{Cu}$-specific magnetization increases in structure of NP (Figure 10), however, not proportionally with ferromagnetic impurity (Table 5).

Besides, this data is visible to proportionally ferromagnetic impurity that concentration of copper in NPS is essential more than in initial targets that is connected with the big distinction partial pressure of copper and corundum.

Let us notice that induced by oxygen vacancies ferromagnetism in NPs $\mathrm{Al}_{2} \mathrm{O}_{3}$ is found recently out in [28]. Amorphous and crystal nanoparticles $\mathrm{Al}_{2} \mathrm{O}_{3}$ have been received by a zol-method with the subsequent annealing at different temperatures. Magnetic measurements have shown that all nanoparticles showed internal at roomtemperature ferromagnetism and magnetization of samples grew $1,25 \times 10^{-3} \mathrm{emu} / \mathrm{g}$ after annealing in vacuum though bulk sample $\mathrm{Al}_{2} \mathrm{O}_{3}$ was paramagnetic. Record indicators of magnetization $\left(4,6 \mathrm{emu} / \mathrm{cm}^{3}\right)$ have been established in the

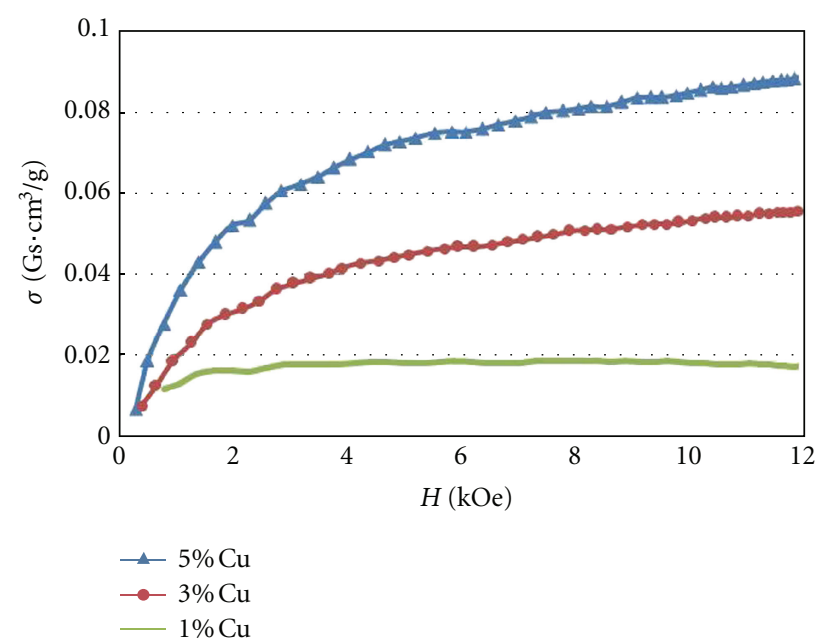

Figure 10: $\mathrm{M}-\mathrm{H}$ curves for $\mathrm{Al}_{2} \mathrm{O}_{3}-\mathrm{Cu}$ nanopowders at $300 \mathrm{~K}$ (program Paint).

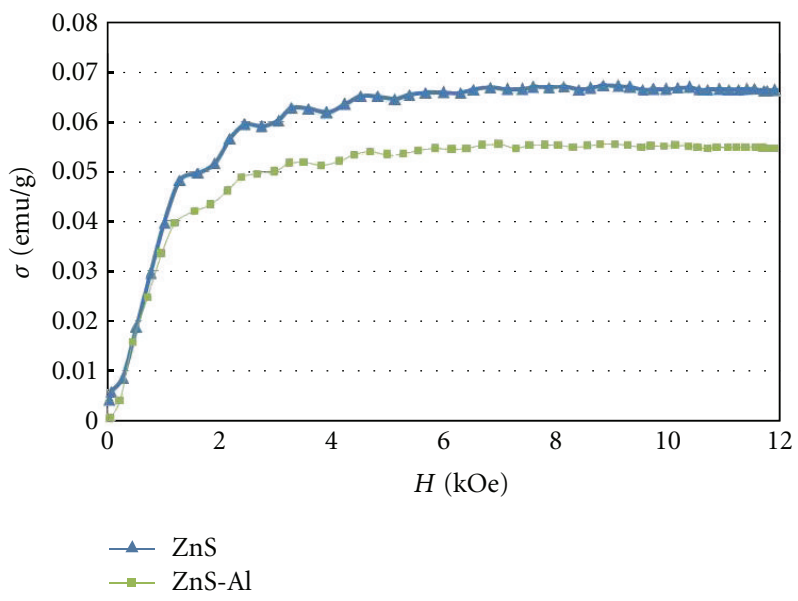

FIGURe 11: Specific magnetization NPs ZnS and ZnS-Al (program Paint).

thin films $\mathrm{Al}_{2} \mathrm{O}_{3}$ [29] received by magnetron dispergation on Si-substrate with the subsequent reannealing in vacuum at $800^{\circ} \mathrm{C}$. Zheng et al. [29] have explained an origin ferromagnetism formation oxides vacancies on the interface between thin films $\mathrm{Al}_{2} \mathrm{O}_{3}$ and a silicon substrate. Thus, experimental acknowledgement ferromagnetism in $\mathrm{Al}_{2} \mathrm{O}_{3}$ in works [27-29] will be coordinated with results of our magnetic measurements in $\mathrm{NPS}_{2} \mathrm{Al}_{2}-\mathrm{Cu}[30,31]$.

The idea of universality superficial ferromagnetism in the inorganic NPs, put forward in works $[24,27]$, has found the acknowledgement in our work c nanopowder on the basis of $\mathrm{ZnS}[32]$ and further works $[33,34]$.

Results of measurements of magnetization NPS ZnS and $\mathrm{ZnS}-\mathrm{Al}$, evaporated in vacuum by means of PEB [32], are resulted in a Figure 11. Our data will quantitatively be coordinated with results of work [33] where also, experimentally and it is theoretically proved that vacancies $\mathrm{Zn}$ can induce internal ferromagnetism $(0,05 \mathrm{emu} / \mathrm{g})$ in not doped $\mathrm{ZnS}$ nanowires. Magnetization of saturation nanocrystalline 
TABLE 5: Composition of the targets and the elemental composition of $\mathrm{Al}_{2} \mathrm{O}_{3}-\mathrm{Al}(\mathrm{Cu})$ NPs as determined by the ICP method.

\begin{tabular}{|c|c|c|c|c|c|}
\hline \multirow{2}{*}{ Target composition (wt \% Cu) } & \multicolumn{5}{|c|}{ Element in PEB NPs (wt. \%) } \\
\hline & $\mathrm{Cu}$ & $\mathrm{Fe}$ & $\mathrm{Cr}$ & $\mathrm{Ni}$ & $\mathrm{Si}$ \\
\hline $\mathrm{Al}_{2} \mathrm{O}_{3}$ & $<0,02$ & $0,0607 \pm 0,01$ & $0,0030 \pm 0,01$ & $<0,00 \pm 1$ & $0,3857 \pm 0,1$ \\
\hline $\mathrm{Al}_{2} \mathrm{O}_{3}-\mathrm{Al}$ & $0,0086 \pm 0,0008$ & $0,0387 \pm 0,004$ & $0,0005 \pm 0,0001$ & $0,0005 \pm 0,0001$ & $0,46 \pm 0,1$ \\
\hline $\mathrm{Al}_{2} \mathrm{O}_{3}(1,72)$ & $1,72 \pm 0,3$ & $0,1335 \pm 0,03$ & $0,0018 \pm 0,0003$ & $<0,0001$ & $0,5080 \pm 0,1$ \\
\hline $\mathrm{Al}_{2} \mathrm{O}_{3}(11,19)$ & $11,19 \pm 1,1$ & $0,0509 \pm 0,005$ & $0,0009 \pm 0,0001$ & $0,0009 \pm 0,0001$ & $0,10 \pm 0,03$ \\
\hline $\mathrm{Al}_{2} \mathrm{O}_{3}(17,22)$ & $17,22 \pm 1,7$ & $0,0628 \pm 0,006$ & $0,0015 \pm 0,0002$ & $0,0008 \pm 0,0001$ & $0,31 \pm 0,03$ \\
\hline
\end{tabular}

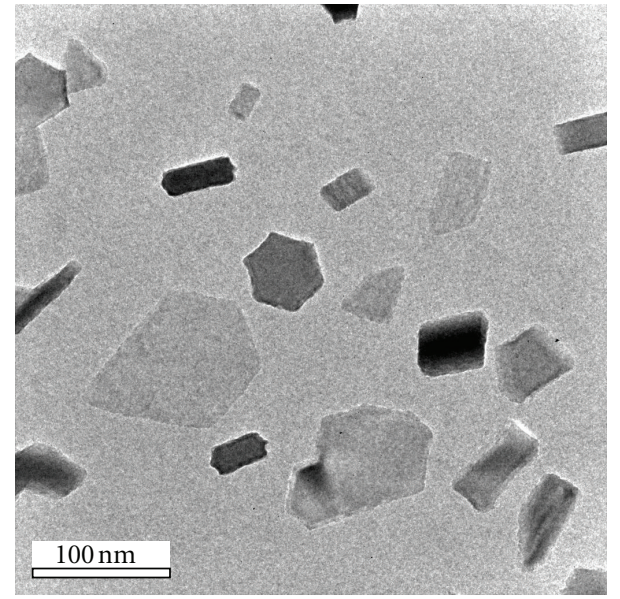

Figure 12: Various structures of the wrong form of $\mathrm{ZnO}$ and $\mathrm{Zn}$ $\mathrm{ZnO}$.

powders received by hydrothermal synthesis, after annealing on $500^{\circ} \mathrm{C}$ in steams $\mathrm{Zn}$ has made $8 \times 10^{-3} \mathrm{emu} / \mathrm{g}$ [34] that is close to indicators of magnetization of ours NPS [32]. Ferromagnetism in doped by not magnetic elements $(\mathrm{Cu}$, C, N) ZnS is predicted in theoretical works [35-37] and it is experimentally established in powders $\mathrm{ZnS}-\mathrm{Cu}\left(\mathrm{M}_{\mathrm{S}} \sim\right.$ $7 \times 10^{-3} \mathrm{emu} / \mathrm{g}$ ) [38] and doped by transitive metals (Cr, Mn, $\mathrm{Fe}, \mathrm{Co}, \mathrm{Ni})$ [39].

At evaporation of targets from $\mathrm{ZnO}$ (at residual pressure $\sim 4 \mathrm{~Pa})$ managed to be received NPS $\mathrm{Zn}-\mathrm{ZnO}$ with $S_{\mathrm{BET}}$ $=56,7 \mathrm{~m}^{2} / \mathrm{g}$ variable structure and various morphology (Figure 12).

Large NPS consist of crystalline particles, differ the big morphological variety, perfection of crystal structure, and essential disorder of the sizes. Separate particles (Figure 13) are core-shell. $\mathrm{Zn}-\mathrm{ZnO}$ structure. It is necessary to notice that in work [40] carbothermic synthesis purposefully received hexagonal nanostructure $\mathrm{ZnO}$ similar on received by us.

\section{Conclusion}

The created installation allows to fabricate NPs oxides with high-specific surface at productivity till $12 \mathrm{~g} /$ hour and specific expenses of energy $\sim 112 \mathrm{~kW}^{*} \mathrm{~h} / \mathrm{g}$ (nearby 5 energy sublimations). At all powders are present fine-crystalline and the coarse-crystalline fractions differing in the size CSR, and also amorphous component. Formation amorphous components in majority of NPs, received by the methods

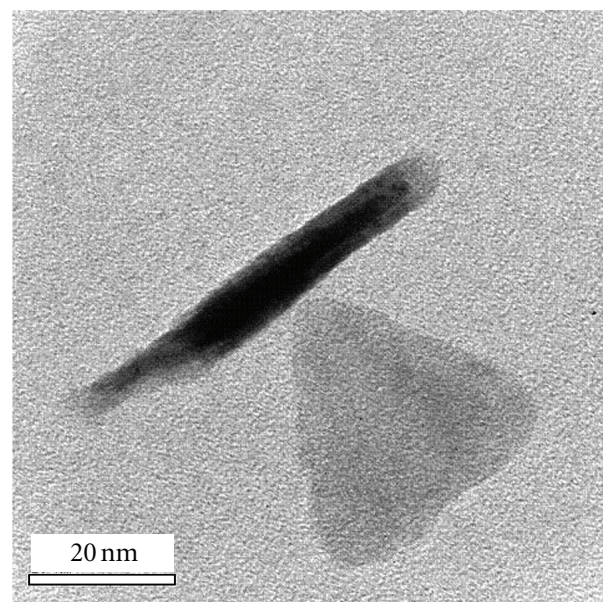

(a)

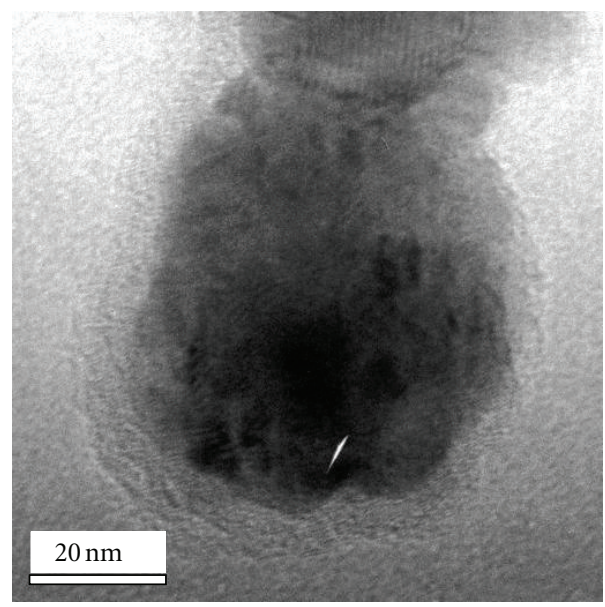

(b)

FIGURE 13: HR TEM images a core-shell $\mathrm{Zn}-\mathrm{ZnO}$ nanostructures.

of electron evaporation with use pulse [31, 41, 42], or continuous beam [43], are their prominent features that makes methods of electronic evaporation very attractive to production and studying of properties NPs in interrelation with their amorphous condition. Formation amorphous components in majority of NPS, the methods of electron evaporation received with use pulse $[31,41,42]$, or a continuous beam [43], are their prominent features that makes methods of electronic evaporation very attractive to production and studying of properties NPS in interrelation with their amorphous condition 
Powders have fractal structure, consist of units in the size from tens to several hundreds nm formed by crystal NP in the size about 3-5 nanometers, with very narrow distribution of particles on the size. NPs have high deficiency of structure that was reflected in their magnetic properties.

\section{Acknowledgments}

The authors are grateful to Dr. Uimin M. A. (IPM UB RAS) for the magnetic measurements, Dr. Moskalenko N. I. (IVTE UB RAS) for the chemical analysis, Dr. S. V. Prjanichnikov (IM UB RAS) for XRD, and to the employees of IEF UB RAS Dr. Medvedev A. I. for XRD, Dr. Mursakaev A. M. for the microscopic analysis, and Demina T. M. for measurement of a specific surface area nanopowder. The works are executed within the limits of the state contract no. 14.740.11.0834 Ministry of Education and Science of Russian Federation.

\section{References}

[1] Y. A. Kotov, "Electric explosion of wires as a method for preparation of nanopowders," Journal of Nanoparticle Research, vol. 5, no. 5-6, pp. 539-550, 2003.

[2] Y. A. Kotov, V. V. Osipov, O. M. Samatov et al., "Properties of powders produced by evaporating $\mathrm{CeO}_{2} / \mathrm{Gd}_{2} \mathrm{O}_{3}$ targets exposed to pulsed-periodic radiation of a $\mathrm{CO}_{2}$ laser," Technical Physics, vol. 49, no. 3, pp. 352-357, 2004.

[3] Y. A. Kotov, O. M. Samatov, M. G. Ivanov et al., "Production and characteristics of composite nanopowders using a fiber ytterbium laser," Technical Physics, vol. 56, no. 5, pp. 652-655, 2011.

[4] U. Popp, R. Herbig, G. Michel, E. Müller, and C. Oestreich, "Properties of nanocrystalline ceramic powders prepared by laser evaporation and recondensation," Journal of the European Ceramic Society, vol. 18, no. 9, pp. 1153-1160, 1998.

[5] V. V. Osipov, M. G. Ivanov, V. V. Lisenkov, and V. V. Platonov, "Highly efficient repetitively pulsed electric-discharge industrial $\mathrm{CO}_{2}$ laser," Quantum Electronics, vol. 32, no. 3, pp. 253$259,2002$.

[6] V. V. Osipov, M. G. Ivanov, V. V. Lisenkov, P. B. Smirnov, and A. L. Filatov, "High-efficient pulsed repetitive $\mathrm{CO}_{2}$ laser for technologic use," in Proceedings of the Digest of Technical Papers-IEEE 11th International Pulsed Power Conference, pp. 1324-1328, July 1997.

[7] M. G. Ivanov, Y. A. Kotov, O. M. Samatov et al., "Production of nanopowders with the help of fiber," Advances in Science and Technology, vol. 62, pp. 22-26, 2010.

[8] S. N. Fadeev, M. G. Golkovski, A. I. Korchagin et al., "Technological applications of BINP industrial electron accelerators with focused beam extracted into atmosphere," Radiation Physics and Chemistry, vol. 57, no. 3-6, pp. 653-655, 2000.

[9] J. D. F. Ramsay and R. G. Avery, "Ultrafine oxide powders prepared by electron beam evaporation," Journal of Materials Science, vol. 9, no. 10, pp. 1689-1695, 1974.

[10] B. Günther and A. Kumpmann, "Ultrafine oxide powders prepared by inert gas evaporation," Nanostructured Materials, vol. 1, no. 1, pp. 27-30, 1992.

[11] J. A. Eastman, L. J. Thompson, and D. J. Marshall, "Synthesis of nanophase materials by electron beam evaporation," Nanostructured Materials, vol. 2, no. 4, pp. 377-382, 1993.
[12] V. F. Popov and Y. N. Gorin, Processes and installations for elektron-ionic technology. High School, Moscow, 1988, http://www.any-book.ru/book/show/id/1270695.

[13] V. G. Il'ves, Y. A. Kotov, S. Y. Sokovnin, and C. K. Rhee, "Use of a pulse electronic beam for production nanopowder oxides," Nanotechnologies in Russia, vol. 2, pp. 96-101, 2007.

[14] V. I. Gushenets, E. M. Oks, G. Y. Yushkov, and N. G. Rempe, "Current status of plasma emission electronics: I. Basic physical processes," Laser and Particle Beams, vol. 21, no. 2, pp. 123-138, 2003.

[15] Y. D. Kozlov, K. I. Nikulin, and Y. S. Titkov, Calculation of Parameters and Design of Radiochemical Plants With Electron Accelerators, Atomizdat, Moscow, Russia, 1976, http://books. google.ru/books?id=PTHVGwAACAAJ\&hl=ru\&source=gbs navlinks_s.

[16] S. Y. Sokovnin and V. G. Il'ves, "Magnetic properties of oxide nanopowders obtained by pulsed electron beam evaporation," Technical Physics Letters, vol. 35, no. 11, pp. 1026-1028, 2009.

[17] L. N. Orlikov and N. L. Orlikov, "Methods for increasing the efficiency of electron beam extraction through a gas-dynamic window," Instruments and Experimental Techniques, vol. 45, no. 6, pp. 784-789, 2002.

[18] V. G. Il’ves, A. S. Kamenetskikh, Y. A. Kotov, A. I. Medvedev, and S. Y. Sokovnin, "Production of nanopowders of metal oxides by evaporation in the pulsed electron beam," Russian Journal of Non-Ferrous Metals, vol. 51, no. 2, pp. 197-200, 2010.

[19] Y. A. Kotov, V. V. Osipov, M. G. Ivanov et al., "Properties of oxide nanopowders prepared by target evaporation with a pulse-periodic $\mathrm{CO}_{2}$ laser," Technical Physics, vol. 47, no. 11, pp. 1420-1426, 2002.

[20] Y. A. Kotov, V. V. Osipov, M. G. Ivanov et al., "Properties of YSZ and CeGdO nanopowders prepared by target evaporation with a pulse-repetitive $\mathrm{CO}_{2}$-laser," Reviews on Advanced Materials Science, vol. 5, no. 3, pp. 171-177, 2003, www.ipme.ru/e-journals/RAMS/no_3503/kotov/kotov.pdf.

[21] L. A. Reznitskii and S. E. Filippova, "Inhibitors of the crystallisation of amorphous materials," Russian Chemical Reviews, vol. 62, pp. 437-446, 1993.

[22] S. V. Gabelkov, R. V. Tarasov, N. S. Poltavtsev, D. S. Logvinkov, and A. G. Mironov, "Phase transformation at crystallization of amorphous zirconia with formation of nanostructure. Questions of a nuclear science and technics," Problems of Atomic Science and Technology, no. 3, pp. 116-120, 2004, Series: Physics Radiating Damages and Radiating Materials Technology, http://vant.kipt.kharkov.ua/TABFRAME2.html.

[23] K. Potzger and S. Zhou, "Non-DMS related ferromagnetism in transition metal doped zinc oxide," Physica Status Solidi, vol. 246, no. 6, pp. 1147-1167, 2009.

[24] A. Sundaresan and C. N. R. Rao, "Ferromagnetism as a universal feature of inorganic nanoparticles," Nano Today, vol. 4, no. 1, pp. 96-106, 2009.

[25] L. P. Larionov, M. G. Zuev, I. M. Strekalov, and S. Y. Sokovnin, "New X-ray contrast means for a basis micro- and nanoparticles tantalate rare-earth elements," Bulletin of Ural Medical Academic Science, vol. 3, p. 37, 2011, http://vestnikural.ru/.

[26] K. Yatsui, T. Yukawa, C. Grigoriu, M. Hirai, and W. Jiang, "Synthesis of ultrafine $\gamma-\mathrm{Al}_{2} \mathrm{O}_{3}$ powders by pulsed laser ablation," Journal of Nanoparticle Research, vol. 2, no. 1, pp. 75-83, 2000

[27] A. Sundaresan, R. Bhargavi, N. Rangarajan, U. Siddesh, and C. N. R. Rao, "Ferromagnetism as a universal feature of nanoparticles of the otherwise nonmagnetic oxides," Physical Review B, vol. 74, no. 16, Article ID 161306, 4 pages, 2006. 
[28] G. Yang, D. Gao, J. Zhang, Z. Shi, and D. Xue, "Evidence of vacancy-induced room temperature ferromagnetism in amorphous and crystalline $\mathrm{Al}_{2} \mathrm{O}_{3}$ nanoparticles," The Journal of Physical Chemistry C, vol. 115, pp. 16814-16818, 2011.

[29] Y. L. Zheng, C. M. Zhen, X. Q. Wang, L. Ma, X. L. Li, and D. L. Hou, "Room-temperature ferromagnetism observed in alumina films," Solid State Sciences, vol. 13, no. 8, pp. 15161519, 2011.

[30] S. Y. Sokovnin, V. G. Il'ves, A. I. Medvedev, A. M. Murzakaev, A. V. Spirina, and M. A. Uimin, "Production of $\mathrm{Al}_{2} \mathrm{O}_{3}$ $\mathrm{Al}(\mathrm{Cu})$ nanopowders by pulsed electron beam evaporation and their basic characteristics," in Proceedings of the 10th International Conference on Modification of Materials with Particle Beams and Plasma Flows, Publishing house of the IAO SB RAS, Tomsk, Russia, 2010, http://www.hcei.tsc.ru/ conf/2010/cat/2010_cmm_bpnn.html.

[31] V. G. Il'ves, A. I. Medvedev, A. M. Murzakaev, S. Y. Sokovnin et al., "Production nanopowder $\mathrm{Al}_{2} \mathrm{O}_{3}-\mathrm{Al}(\mathrm{Cu})$ evaporation by a pulse electronic beam and their basic characteristics," Physics and Chemistry of Materials Treatmen, vol. 2, pp. 18-25, 2011, http://www.imet.ac.ru/fxom/.

[32] V. G. Il'ves and S. Y. Sokovnin, "Research of magnetic properties nanopowder $\mathrm{ZnS}$ received by means of a pulsed electron beam. Interhigh school," in Proceedings of the Problems of Spectroscopy and Spectrometry, vol. 26, pp. 237-242, Ekaterinburg, Russia, 2010, USTU-UPI.

[33] G. Zhu, S. Zhang, Z. Xu, J. Ma, and X. Shen, "Ultrathin $\mathrm{ZnS}$ single crystal nanowires: controlled synthesis and roomtemperature ferromagnetism properties," Journal of the American Chemical Society, vol. 133, no. 39, pp. 15605-15612, 2011.

[34] Y. Zhang, H. Qin, Y. Bao, and J. Hu, "Study of ferromagnetism in $\mathrm{Bi}_{2} \mathrm{~S}_{3}$ and $\mathrm{ZnS}$ nanocrystalline powders," Physica $B$ \& $C$, vol. 406, pp. 4661-4665, 2011.

[35] C. W. Zhang and S. S. Yan, "First-principles prediction of halfmetallic ferromagnetism in Cu-doped ZnS," Journal of Applied Physics, vol. 107, no. 4, Article ID 043913, 3 pages, 2010.

[36] C. W. Zhang, S. S. Yan, P. J. Wang, and Z. Zhang, "Densityfunctional theory study on ferromagnetism in $\mathrm{N}$ : ZnS," Chemical Physics Letters, vol. 496, no. 1-3, pp. 46-49, 2010.

[37] H. Chen, "First-principles study on the magnetic property of C-doped wurtzite ZnS," Physics Letters, Section A, vol. 375, no. 24, pp. 2444-2447, 2011.

[38] F. J. Owens, L. Gladczuk, R. Szymczak et al., "High temperature magnetic order in zinc sulfide doped with copper," Journal of Physics and Chemistry of Solids, vol. 72, no. 6, pp. 648-652, 2011.

[39] J. Xie, "First-principles study on the magnetism in ZnS-based diluted magnetic semiconductors," Journal of Magnetism and Magnetic Materials, vol. 322, no. 19, pp. 37-41, 2010.

[40] Z. Fan and J. G. Lu, "Zinc oxide nanostructures: synthesis and properties," Journal of Nanoscience and Nanotechnology, vol. 5, no. 10, pp. 1561-1573, 2005.

[41] V. G. Il'ves and S. Y. Sokovnin, "Production of $\mathrm{ZnO}$ and $\mathrm{Zn}$ $\mathrm{ZnO}$ nanopowders using evaporation by a pulsed electron beam in low-pressure gas," Nanotechnologies in Russia, vol. 6, no. 1-2, pp. 137-143, 2011.

[42] S. Y. Sokovnin, V. G. Il'ves, A. I. Medvedev et al., "Medvedev AI et al (2011) Pulse electronic evaporation nanopowder $\mathrm{ZnO}-\mathrm{Zn}$ doped copper," in Proceeding of the 4th All-Russia Conference on Nanomaterials, p. 574, Institute of Metals and Materials Science, Moscow, Russia, http://nano.imet-db.ru/Materials.asp.
[43] V. I. Lysenko, S. Bardakhanov, A. Korchagin et al., "Possibilities of production of nanopowders with high power ELV electron accelerator," Bulletin of Materials Science, vol. 34, no. 4, pp. 677-681, 2011, http://trove.nla.gov.au/work/157892775. 

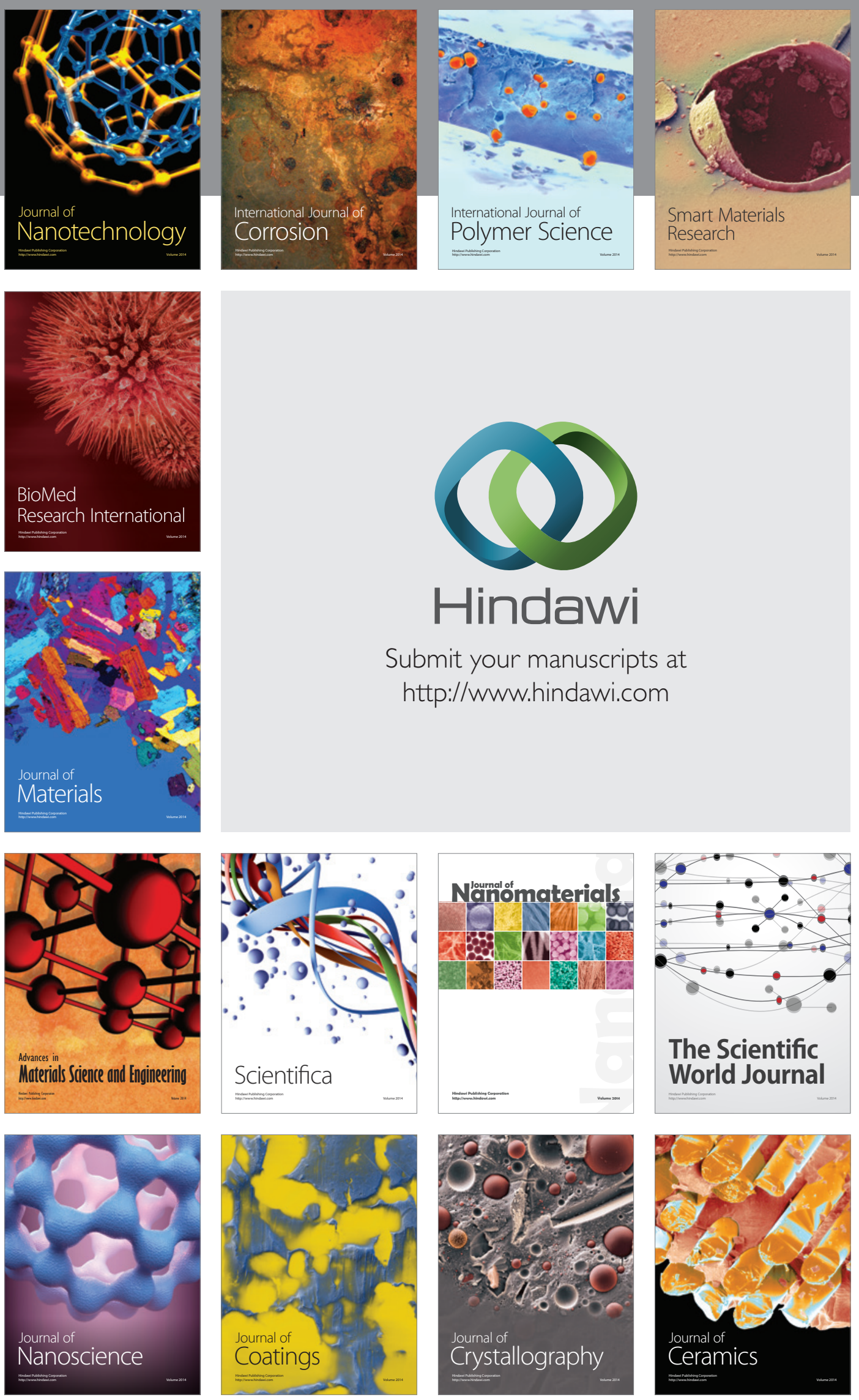

The Scientific World Journal

Submit your manuscripts at

http://www.hindawi.com

\section{World Journal}

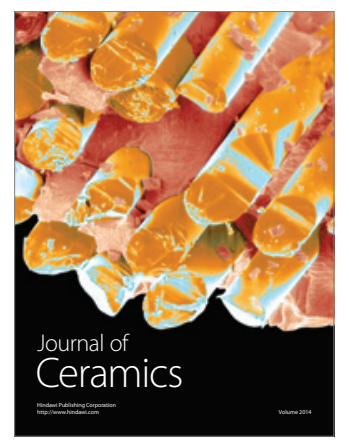

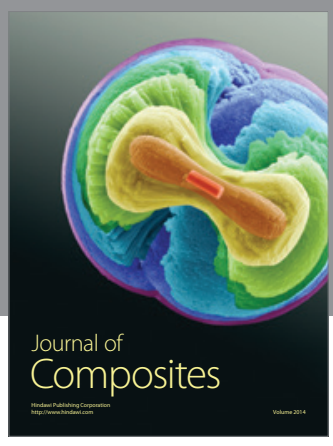
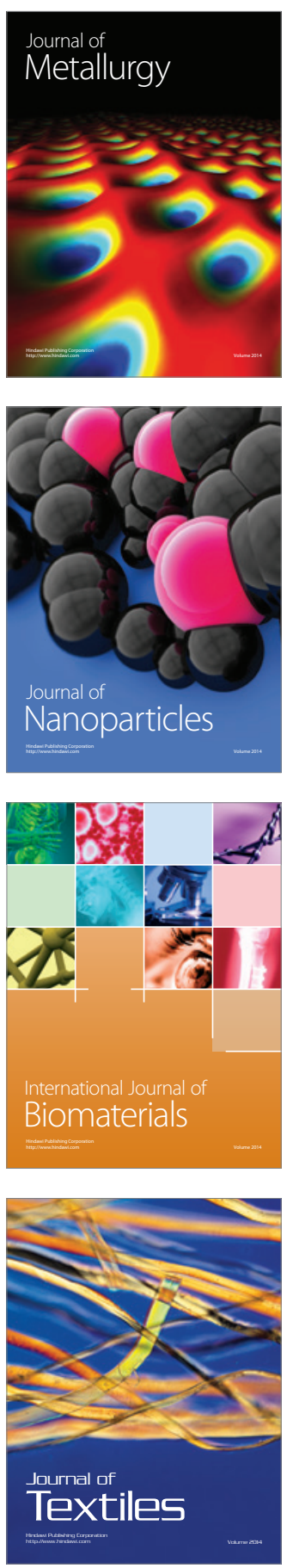